Original Research Article

\title{
The comparisons of the efficacy of two fixed dose combinations, i.e. Salmeterol and Fluticasone vs. Formoterol and Tiotropium bromide in moderate to severe COPD patients
}

\author{
Dharmaraj B. ${ }^{1}$, Prashanth G. ${ }^{2 *}$, Basavaraj S. ${ }^{3}$
}

\begin{abstract}
${ }^{1}$ Department of Pharmacology,
${ }^{2}$ Department of Medicine,

${ }^{3}$ Department of Pulmonary

Medicine, Basaveshwara

Medical College \& Hospital,

Chitradurga, Karnataka, India
\end{abstract}

Received: 23 April 2018

Accepted: 23 May 2018

\section{*Correspondence to: \\ Dr. Prashanth G., \\ Email: drprashanthg@ \\ gmail.com}

Copyright: () the author(s), publisher and licensee Medip Academy. This is an openaccess article distributed under the terms of the Creative Commons Attribution NonCommercial License, which permits unrestricted noncommercial use, distribution, and reproduction in any medium, provided the original work is properly cited.

\begin{abstract}
Background: Bronchodilators are essential for symptomatic management of all stages of chronic obstructive pulmonary disease (COPD). For patients whose COPD is not sufficiently controlled by monotherapy, combining a B2-agonist with either inhaled steroid or anticholinergic drug is a convenient way of delivering treatment. Currently, there is no documentation to say that one drug is superior to other or the contrary, but a combination of two drugs is more effective than giving single drug alone in patients suffering from COPD.

Methods: The study was prospective, open labelled, randomized, comparative interventional clinical study conducted by the Departments of Pharmacology and Medicine, Basaveshwara Medical College and Hospital, Chitradurga in 60 moderates to severe COPD patients.

Results: Both the treatments i.e. Salmeterol/Fluticasone and Tiotropium/Formoterol were equally effective as far as the improvement of the lung functions and Borg dyspnoea score are concerned. The difference in improvement with the combination of Salmeterol/Fluticasone was not statistically significant $(\mathrm{p}>0.05)$ compared to the combination of Tiotropium/Formoterol. However, Salmeterol/Fluticasone was found to be better than Tiotropium/Formoterol in improving the lung function of moderate to severe COPD patients.

Conclusions: Salmeterol/Fluticasone is efficacious and better than Tiotropium /Formoterol combination for maintenance therapy in moderate to severe COPD patients.
\end{abstract}

Keywords: COPD, FDC, LABA, ICS, Inhaled bronchodilators, Tiotropium

\section{INTRODUCTION}

Chronic obstructive pulmonary disease (COPD) is a most common respiratory disorder and a major public health problem with increasing morbidity and mortality throughout the world. It is associated with an enhanced inflammatory response in the airways and the lung to noxious particles or gases. Therefore, bronchial relaxation and inflammatory response suppression represent a mechanistic approach in the treatment of COPD that might improve symptoms and reduce exacerbations. ${ }^{1}$
COPD is the fourth leading cause of death in the world and is projected to be $3 \mathrm{rd}$ by $2020 .{ }^{1}$ Eighty million people have moderate to severe COPD. ${ }^{1}$ Overall, epidemiological studies from various countries using standardized methods and spirometry estimate COPD prevalence as being between 5 and $25 \%$ of the population aged over 40 years. ${ }^{2}$ This trend is due to the risk factors and the changing age structure of the world's population. ${ }^{3}$

COPD is a preventable and treatable disease with some significant extra pulmonary effects that may contribute to the severity in individual patients. Causes of COPD are 
multifactorial, commonest being cigarette smoking. Pathological factors including genetic factors (e.g. $\alpha-1$ antitrypsin deficiency) also play a role in the development of the disease. ${ }^{1,4}$ The inflammatory response is characterised by bronchial and alveolar infiltration of neutrophils and the presence of an increased number of macrophages and $\mathrm{T}$ lymphocytes. Patient with COPD complicated by corpulmonale often have chronic respiratory failure as a complication of respiratory infection. ${ }^{3}$

Global Initiative for Chronic Obstructive Lung Disease (GOLD) has established a level of evidence that is

- Bronchodilators are essential for the symptomatic treatment of COPD

- The principal bronchodilator treatments include $\beta-2$ agonists, anticholinergics and methylxanthines

- Regular treatment with long acting bronchodilator is more effective and convenient than treatment with short acting bronchodilator. ${ }^{5}$

The current pharmacological therapy for COPD is limited in the reduction of high mortality associated with progressive disease, as recently reported by the trial Towards a Revolution in COPD Health (TORCH). ${ }^{6}$ Indeed, TORCH has demonstrated that the reduction in mortality could not reach significance. However, our ultimate aims are to improve therapeutic outcomes by reducing the symptoms, especially dyspnoea, to increase exercise capacity, reduce exacerbations which ultimately improve quality of life. ${ }^{7}$

Management of a stable COPD patient includes, reduction of exposure to risk factors by smoking cessation. Optimising expiratory flow by means of bronchodilator drugs, such as long-acting b2 agonists(LABAs) and anticholinergic agents. Reducing pulmonary inflammation by corticosteroids and managing acute exacerbations. ${ }^{8,9}$ The present COPD treatment guidelines recommend the use of long-acting bronchodilators for patients with moderate (stage II; FEV $150-80 \%$ predicted) to very severe (stage IV; FEV $1<30 \%$ predicted) COPD patients. ${ }^{10}$ Nowadays, the pharmacological treatment of COPD is based on using bronchodilators, which represent the mainstay of COPD therapy and inhaled glucocorticoids (ICSs) to target both symptoms and inflammation. ${ }^{1}$ Longacting b2-adrenoceptoragonist (LABA) + ICS combinations demonstrated an additive effect in COPD treatment. ${ }^{11}$

The combination of inhaled corticosteroids (ICSs) and long-acting b2 agonists (LABAs), or LABAs and anticholinergics has become an efficient alternative to single therapies. ${ }^{1}$ The rationale for using these compounds lies in the fact that they have different molecular mechanisms of action and consequently, their combined use could maximize the clinical benefits for patients suffering from this debilitating disease. ${ }^{1}$
Inhaled beta-adrenergic therapy is standard in the long term management of patients with COPD and a variety of such agents are currently available for use via a metered dose inhaler. Though there is little evidence to recommend one agent over another, however bronchodilators are required in symptomatic management of all stages of COPD. ${ }^{12,13}$ Tobacco smoking continues to be a major cause of COPD, as well as of many other diseases. A worldwide decline in tobacco smoking would result in decrease in the prevalence of COPD and other smoking related diseases. ${ }^{14}$

Tiotropium bromide, a long acting anticholinergic also has been shown to reduce exacerbations and COPD related hospitalizations compared with ipratropium. ${ }^{15}$ In various COPD populations, the combination of ICS plus LABA for maintenance therapy, including the combination medication of fluticasone propionate $250 \mathrm{ug}+$ salmeterol 5 ug (FSC), has been associated with a lower risk for COPD related hospitalizations including acute exacerbations, emergency department visits and health care costs compared with ipratropium, a short acting anticholinergic. ${ }^{16,17}$ The use of appropriate medications for the treatment of COPD is essential to improve patient's quality of life and minimize the substantial burden of illness on the health care system. ${ }^{18}$

Dalal et al, reported an observational study comparing Fluticasone and Salmeterol combination (FSC) verses anticholinergics (Ipratropium and Tiotropium) in a Medicare eligible population. ${ }^{19,20}$ The study concludes that initial maintenance therapy with FSC may offer clinical and cost benefit in comparison with short and long acting anticholinergics.

Another recent study has also investigated the efficacy of combining Tiotropium with ICS and LABA therapy (triple therapy) in patients with severe COPD. The study concludes improved efficacy with triple therapy than with combination of ICS and LABA. ${ }^{21}$ Considering that the primary goal of COPD management is the prevention and reduction of exacerbations and this study shows that patients receiving triple therapy had lower risk for COPD exacerbations and may offer some clinical benefits. ${ }^{22}$

Subsequently, D’Urzo and colleagues demonstrated the addition of formoterol ( $12 \mu \mathrm{g}$ twice daily) to ipratropium bromide $(40 \mu \mathrm{g}$ four times a day) is more effective than the addition of salbutamol $(200 \mu \mathrm{g}$ four times a day) in patients with COPD who required combined bronchodilator therapy. ${ }^{23}$ This finding clearly indicates that long-acting 32 agonists may represent the most effective option for combination therapy with an anti-muscarinic agent.

Since the present study is the first to compare the two FDCs and hence the study was taken up to compare the clinical outcomes in terms of efficacy of two FDCs as initial maintenance therapy for moderate to severe COPD patients. 
Aims and objectives of the study was to compare the efficacy of two fixed dose combinations i.e. Salmeterol and Fluticasone vs. Formoterol and Tiotropium bromide in moderate to severe COPD patients

\section{METHODS}

\section{Study protocol}

This is a prospective, open labelled, randomized, comparative interventional clinical study conducted by the Departments of Pharmacology and Medicine, Basaveshwara Medical College and Hospital, Chitradurga in 60 patients. Study was in accordance with the principles of good clinical practice and declaration of Helsinki. Written informed consent was obtained from all the patients enrolled for the study.

\section{Study sample}

There were two groups each of 30 moderate to severe COPD patients of either sex were randomly allocated to receive two different FDC regime treatments. The patients were screened for eligibility in the out-patient clinic, Department of Medicine according to following inclusion and exclusion criteria.

\section{Inclusion criteria}

- 20-75 years of age of either sex

- Clinically diagnosed cases of COPD of moderate to severe variety as per GOLD criteria

- $\quad$ Requirement of combination of LABA and ICS and LABA with long acting anticholinergic

- $\quad$ Patients ready to provide written informed consent to the study protocol

\section{Exclusion criteria}

- Patients of bronchial asthma

- Use of supplemental oxygen

- Routine use of nebulised bronchodilator therapy

- Unstable concurrent medical problems like uncontrolled hypertension, Diabetes Mellitus, Pulmonary tuberculosis

\section{Drug treatment}

The patients were randomly assigned with the help of enveloped grouping system to get allotted to either of two groups:

- $\quad$ Group I: Salmeterol $125 \mu \mathrm{g}$ and Fluticasone $250 \mu \mathrm{g}$ (SEROFLO 2 puffs b.d by inhalation) for a period of 8 weeks

- $\quad$ Group II: Formoterol $12 \mu \mathrm{g}$ and Tiotropium bromide $9 \mu \mathrm{g}$ (DUOVA 2 puffs o.d by inhalation) for a period of 8 weeks
Available commercial preparations (same brand) were used throughout the study period. SEROFLO and DUOVA marketed by CIPLA limited were used.

Compliance was ensured by interviewing the patient at every visit.

\section{Clinical assessment}

It was carried out in all the patients in terms of efficacy of the treatment

\section{Efficacy assessment}

The patients were assessed every 2 week for 8 weeks to see the status of improvement by observing:

\section{Pulmonary function tests}

By spirometry i.e. forced vital capacity (FVC), forced expiratory volume in first second $\left(\mathrm{FEV}_{1}\right)$, peak expiratory flow rate (PEFR) and ratio of $\mathrm{FEV}_{1} / \mathrm{FVC}$ were measured and recorded. Borg score for dyspnoea was noted.

\section{Data collection}

The data collection was prospective in nature. The period of observation was for 8 weeks on one therapeutic regime. Eligible subjects were interviewed, and Information was collected regarding the efficacy with the use of two different fixed dose combinations.

\section{Data analysis}

The data obtained were expressed as Mean \pm Standard Error of mean (SEM). For intergroup, unpaired $\mathrm{T}$ test was used to analyse categorical variables, where ever appropriate. p-value $<0.05$ was considered as statistically significant. All statistical analysis was performed with the use of SPSS software package.

\section{RESULTS}

\section{Efficacy assessment}

\section{Lung function tests}

All the patients were subjected to spirometry. The predicted values were calculated automatically by the spirometer according to patient's age, sex, height and weight.

\section{Forced vital capacity (FVC)}

The baseline FVC values in both the treatment groups were comparable $(\mathrm{p}=0.437)$ and did not have any implication on statistical comparison. 
On intergroup analysis, no significant difference in the FVC value was observed at 4 and 8 weeks $(p=0.527$ at 4 weeks and $\mathrm{p}=0.457$ at 8 weeks) as shown in table 1 . It means that both the treatments were equally effective in improving FVC. However, improvement in group $\mathrm{I}$ is more compared to group II as shown in Table 1.

Table 1: Comparison of FVC (litres) in both groups at different intervals.

\begin{tabular}{|llll|}
\hline Groups & Baseline & Week 4 & Week 8 \\
\hline Group I & $2.05 \pm 0.16$ & $2.70 \pm 0.16$ & $3.0 \pm 0.14$ \\
\hline Group II & $2.10 \pm 0.17$ & $2.50 \pm 0.16$ & $2.78 \pm 0.15$ \\
\hline
\end{tabular}

All values are expressed as mean \pm SEM

\section{Forced expiratory volume in first second $\left(F E V_{1}\right)$}

The spirometric readings obtained at different time intervals are shown in Table 2 . The baseline values in both the groups at 0 week shows that the severity of illness was comparable at the time of admission in the two groups $(\mathrm{p}=$ 0.834).

Intergroup analysis showed that there is no significant difference in the improvement seen at 4 weeks $(p=0.452)$ and 8 weeks $(p=0.460)$ in the parameter concerned. It shows that both the treatments improved $\mathrm{FEV}_{1}$ to the same extent. However, improvement in group $\mathrm{I}$ is more compared to group II as shown in Table 2.

Table 2: Comparison of FEV 1(litres) in both groups at different intervals.

\begin{tabular}{|llll|}
\hline Groups & Baseline & Week 4 & Week 8 \\
\hline Group I & $1.19 \pm 0.16$ & $1.62 \pm 0.15$ & $1.94 \pm 0.13$ \\
\hline Group II & $1.24 \pm 0.13$ & $1.48 \pm 0.15$ & $1.79 \pm 0.11$ \\
\hline
\end{tabular}

All values are expressed as mean \pm SEM

\section{Ratio of FEV / FVC}

At the baseline values it was observed that this ratio was decreased in both the groups and both the values are comparable. With treatment it improved in both the groups

Intergroup statistical comparison of this ratio showed that there was no significant difference at 4 weeks $(p=0.723)$ and 8 weeks $(p=0.648)$ between the two groups. However, improvement in group I is more compared to group II as shown in Table 3.

\section{Peak expiratory flow rate (PEFR)}

The baseline PEFR values in both the treatment groups were comparable $(\mathrm{p}=0.417)$ and did not have any implication on statistical comparison. Intergroup analysis showed that there was no statistical significant difference in improvement at 4 weeks $(p=0.492)$ and at 8 weeks $(p$ $=0.413)$. However, improvement in group $\mathrm{I}$ is more compared to group II as shown in Table 4.
Table 3: Comparison of FEV1/FVC (\%) in both groups at different intervals.

\begin{tabular}{|llll|}
\hline Groups & Baseline & Week 4 & Week 8 \\
\hline Group I & $44.63 \pm 3.71$ & $56.10 \pm 2.28$ & $65.50 \pm 2.08$ \\
\hline Group II & $45.37 \pm 2.60$ & $54.20 \pm 2.79$ & $61.30 \pm 2.43$ \\
\hline
\end{tabular}

All values are expressed as mean \pm SEM

Table 4: Comparison of PEFR (litres/sec) in both groups at different intervals.

\begin{tabular}{|llll|}
\hline Groups & Baseline & Week 4 & Week 8 \\
\hline Group I & $2.32 \pm 0.22$ & $2.99 \pm 0.22$ & $3.73 \pm 0.24$ \\
\hline Group II & $2.44 \pm 0.35$ & $2.82 \pm 0.31$ & $3.52 \pm 0.28$ \\
\hline
\end{tabular}

All values are expressed as mean \pm SEM

\section{Borg scores for Dyspnoea in both groups}

On intergroup analysis, no significant difference was found between the two groups and the improvement seen was found to be comparable both at 2 weeks $(p=0.341)$ and at 4 weeks $(\mathrm{p}=0.431)$. However, at week 6 and week 8 there was a significant difference $(p<0.05)$ between two groups at respective intervals as shown in Table 5.

Table 5: Borg score for Dyspnoea in both groups at different time intervals.

\begin{tabular}{llllll|} 
Treatment & Baseline & Week & Week & Week & Week \\
& $\mathbf{2}$ & $\mathbf{4}$ & $\mathbf{6}$ & $\mathbf{8}$ \\
\hline Group I & $10(50)$ & $9(45)$ & $4(20)$ & $1(5)^{*}$ & $1(5)^{*}$ \\
\hline Group II & $9(45)$ & $8(40)$ & $5(25)$ & $4(20)^{*}$ & $3(15)^{*}$ \\
\hline
\end{tabular}

\section{DISCUSSION}

The present study was conducted in a prospective randomized manner to compare the two treatment groups i.e. Salmeterol and Fluticasone vs. Formoterol and Tiotropium bromide in moderate to severe COPD patients. All the patients were subjected to spirometry for evaluations of the lung functions viz. FVC, $\mathrm{FEV}_{1}$, $\mathrm{FEV}_{1} / \mathrm{FVC}$ and PEFR.

There was a marked improvement in the FVC post treatment in both the groups. FVC values improved significantly at 4 weeks and at 8 weeks. Maximum improvement was seen at 8 weeks. Both the treatments when compared were found to be equally effective in improving the FVC but the difference was not statistically significant $(\mathrm{p}>0.05)$.

FEV1 values also showed significant improvement in both the groups at 4 weeks and at 8 weeks as compared to their respective baseline. When the two groups were compared between themselves, it was found that both treatments were equally efficacious in improving FEV1. 
The ratio of $\mathrm{FEV}_{1} / \mathrm{FVC}$ in both the groups showed improvement which was significant when compared to baseline values. The improvement in these values can be attributed to a better improvement in $\mathrm{FEV}_{1}$ as compared to FVC after treatment. When the improvement was compared in the two groups, both the groups did not show any statistical significant difference with the extent of improvement.

The PEFR improved significantly with both the treatments when compared to the baseline values at 4 weeks as well as at 8 weeks. In group $\mathrm{I}$, there was a significant improvement from 4 weeks to 8 weeks also while in group II, the improvement sustained at 8 weeks showing that the treatment with Salmeterol and Fluticasone was relatively better clinically.

Overall the lung functions showed improvement in both the groups with maximum improvement seen at 8 weeks. This is possibly because of the synergistic activity of long acting $\beta_{2}$ agonist and inhaled corticosteroid. There is now evidence that suggest $\beta_{2}$ agonists and corticosteroids target different and complementary aspects of the inflammatory process and that both the classes of treatment are needed for optimal control in most COPD patients. Moreover, corticosteroids protect against the loss of $\beta_{2}$ receptors during long term LABA therapy. Hence the fixed dose combinations of ICS and LABA may be more costeffective than giving the two drugs separately. The results of the present study show that there was progressive improvement in lung function right from the beginning of the study and it continued upto 8 weeks. In both the groups lung function showed a definite improvement at the end of the study period as compared to the baseline values. The results may be attributed to the simultaneous delivery of two potent drugs.

Welte $\mathrm{T}$, et al, investigated the efficacy of combining Tiotropium with ICS and LABA therapy (triple therapy) in patients with severe COPD. The study concludes improved efficacy with triple therapy than with combination of ICS and LABA. ${ }^{21}$

D'Urzo AD et al, demonstrated that the addition of formoterol $(12 \mu \mathrm{g}$ twice daily) to ipratropium bromide ( $40 \mu \mathrm{g}$ four times a day) is more effective than the addition of salbutamol $(200 \mu \mathrm{g}$ four times a day) in patients with COPD who required combined bronchodilator therapy. ${ }^{23}$

The overall results of the present study show that both the treatments i.e. Salmeterol/ Fluticasone and Tiotropium/ Formoterol were equally effective as far as improvement of the lung functions and Borg dyspnoea scores are concerned while the combination Salmeterol/ Fluticasone was found to be better than Tiotropium/ Formoterol in improving the lung function of moderate to severe COPD patients.

\section{CONCLUSION}

The combinations of Salmeterol/Fluticasone and Tiotropium/Formoterol showed a significant improvement not only in the lung functions but also Borg's dyspnoea score. Thus, from the results observed, Salmeterol/Fluticasone is efficacious and better than Tiotropium /Formoterol combination. Since the LABA's and ICS complement the effect of each other pharmacologically, it may be a good idea to use the FDCs of the $\beta_{2}$ agonists and inhalational steroids for maintenance therapy in moderate to severe COPD patients to achieve a better therapeutic control with an improved compliance.

Funding: No funding sources

Conflict of interest: None declared

Ethical approval: The study was approved by the Institutional Ethics Committee (IEC NO.121/2017/Pharma-Med.)

\section{REFERENCES}

1. Global Initiative for Chronic Obstructive Lung Disease (GOLD). Global strategy for the diagnosis, management and prevention of chronic obstructive pulmonary disease (Online); Updated 2017. Available at: http://www.goldcopd.com

2. Mannino DM. The natural history of chronic obstructive pulmonary disease. Pneumonol Alergol Pol. 2011;79:139-43.

3. Lopez AD, Shibuya K, Rao C, Mathers CD, Hansell AL, Held LS, et al. Chronic obstructive pulmonary disease: current burden and future projections. Eur Respir J. 2006;27:397-412.

4. Pauwels RA, Buist AS, Calverley P, Jenkins CR, Hurd SS. Global strategy for the diagnosis, management, and prevention of chronic obstructive pulmonary disease. Am J Respir Crit Care Med. 2001;163:125676.

5. Barnes PJ. Emerging pharmacotherapies for COPD. Chest. 2008;134:1278-86.

6. Calverley PM, Anderson JA, Celli B. Salmeterol and fluticasone propionate and survival in chronic obstructive pulmonary disease. $N$ Engl $\mathrm{J}$ Med. 2007;22:775-89.

7. Mahler DA. The effect of inhaledbeta2-agonists on clinical outcomes inchronic obstructive pulmonary disease. J Allergy ClinImmunol. 2002;110:S298-303.

8. Calverley PM. Modern treatment of chronic obstructive pulmonary disease. Eur Respir J. 2001;18:60s-6s.

9. Sin DD, McAlister FA, Man SF, Anthonisen NR. Contemporary management of chronic obstructive pulmonary disease: scientific review. JAMA 2003;290:2301-12.

10. Rabe KF, Hurd S, Anzueto A. Global strategy for the diagnosis, management, and prevention of chronic obstructive pulmonary disease: GOLD executive summary. Am J Respir Crit Care Med. 2007;176(6):532-55. 
11. Cazzola M, Dahl R. Inhaled combination therapy with long-acting beta2-agonists and corticosteroids in stable COPD. Chest. 2004;126:220-37.

12. Gross NJ. Chronic obstructive pulmonary disease: current concepts and therapeutic approaches. Chest 1990;97:19-23.

13. American Thoracic Society. Standards for the diagnosis and care of patients with chronic obstructive pulmonary disease (COPD) and asthma. Am Rev Respir Dis. 1987;136:225-44.

14. Anthonisen NR, Skeans MA, Wise RA, Manfreda J, Kanner RE, Connett JE. The effects of a smoking cessation intervention on 14.5-year mortality: a randomized clinical trial. Ann Intern Med. 2005;142:233-9.

15. Celli BR, MacNee W. ATS/ERS Task Force. Standards for the diagnosis and treatment of patients with COPD: A summary of the ATS/ERS position paper. Eur Respir J. 2004;23:932-46.

16. Oostenbrink JB, Rutten-van Mölken MP, Al MJ, van Noord JA, Vincken W. One-year cost-effectiveness of tiotropium versus ipratropium to treat chronic obstructive pulmonary disease. Eur Respir J. 2004;23:241-9.

17. Wedzicha JA, Calverley PMA, Seemungal TA. The prevention of chronic obstructive pulmonary disease exacerbations by salmeterol/ fluticasone propionate or tiotropium bromide. Am J Respir Crit Care Med. 2008;177:19-26.

18. Akazawa M, Hayflinger DC, Stanford RH, Blanchette CM. Economic assessment of total health care for chronic obstructive pulmonary disease. Am J Manag Care. 2008;14:438-48.

19. Dalal AA, Petersen H, Simoni-Wastila L, Blanchette CM. Healthcare costs associated with initial maintenance therapy with fluticasone propionate 250 $\mu \mathrm{g} / \mathrm{salmeterol} 50 \quad \mu \mathrm{g} \quad$ combination versus anticholinergic bronchodilators in elderly US Medicare eligible beneficiaries with COPD. J Med Econ. 2009;12:339-47.

20. Delea TE, Hagiwara M, Dalal AA, Stanford RH, Blanchette CM. Healthcare use and costs in patients with chronic bronchitis initiating maintenance therapy with fluticasone/salmeterolvs other inhaled maintenance therapies. Curr Med Res Opin. 2009;25:1-13.

21. Welte T. Optimising treatment for COPD - new strategies for combination therapy. Int J Clin Pract. 2009;63:1136-49.

22. Guyatt GH, Townsend M, Pugsley SO, Keller JL, Short HD, Taylor DW, et al. Bronchodilators in chronic airflow limitation: effects on airway function, exercise capacity and quality of life. Am Rev Respir Dis. 1987;135:1069-74.

23. D'Urzo AD, De Salvo MC, Ramirez-Rivera A, Almeida J, Sichletidis L, Rapatz G, et al. In patients with COPD, treatment with a combination of formoterol and ipratropium is more effective than a combination of salbutamol and ipratropium: a 3week, randomized, double-blind, within-patient, multicenter study. Chest. 2001;119:1347-56.

Cite this article as: Dharmaraj $\mathrm{B}$, Prashanth $\mathrm{G}$, Basavaraj S. The comparisons of the efficacy of two fixed dose combinations, i.e. Salmeterol and Fluticasone vs. Formoterol and Tiotropium bromide in moderate to severe COPD patients. Int J Basic Clin Pharmacol 2018;7:1351-6. 